\title{
El álbum visual como nueva forma promocional de la industria de la música: el caso de Let England Shake de PJ Harvey y Seamus Murphy
}

\section{Ana María Sedeño-Valdellós ${ }^{1}$}

Recibido: 2015-03-24

Enviado a pares: 2015-03-25
Aprobado por pares: 2015-04-24

Aceptado: 2015-05-07

DOI: 10.5294/pacla.2016.19.1.5

Para citar este artículo / to reference this article / para citar este artigo

Sedeño-Valdellós, A. M. (Marzo de 2016). El álbum visual como nueva forma promocional de la industria de la música: el caso de Let England Shake de PJ Harvey y Seamus Murphy. Palabra Clave, 19(1), 105-132. DOI: 10.5294/pacla.2016.19.1.5

\section{Resumen}

El nuevo modelo de negocio para la industria fonográfica comienza a basarse en los contenidos digitales. Varios autores han estudiado y afirman que la industria musical experimenta un giro hacia el contenido audiovisual. Esto se enmarca en una nueva etapa de estética audiovisual caracterizada por la transmedialidad y la convergencia de medios en torno a formatos audiovisuales complejos. El álbum visual, como concepto formado por videoclips de todas las canciones de un disco, se consolida como un nuevo formato de promocional musical, híbrido entre cine y video musical. En el trabajo se realizará un análisis del álbum visual Let England Shake (PJ Harvey \& Seamus Murphy, 2011), con unos criterios que tratan de buscar motivos visuales que generen continuidad, unidad temática y narrativa para demostrar su intensa coherencia con el álbum musical precedente. Se trata de definir el álbum visual y comenzar a delimitarlo frente a otros tipos de

1 Universidad de Málaga, España.valdellos@uma.es 
productos audiovisuales, así como examinar sus posibilidades de creación de sentido en la generación de una narrativa personal diferenciada para un artista/grupo musical.

\section{Palabras clave}

Videoclip musical, álbum visual, estética audiovisual contemporánea (Fuente: Tesauro de la Unesco). 


\section{The Visual Album as a New Promotional Form of the Music Industry: The Case of Let England Shake by PJ Harvey and Seamus Murphy}

\section{Abstract}

The new business model for the music industry begins to rely on digital content. Several authors have studied and say that the music industry is experiencing a shift towards audiovisual content. This is part of a new stage characterized by the visual aesthetics transmediality and media convergence on complex media formats. The visual album, as a concept consisting of video clips of all the songs on a disc, is positioned as a new form of musical promotion, hybrid between film and music video. The article analyzes the visual album Let England Shake (PJ Harvey \& Seamus Murphy, 2011), with a few criterion that seek visual motifs that generate continuity, thematic unity and narratives in order to demonstrate its intense musical coherence with the previous album made. This is to define the visual album and start to delimit the other types of audiovisual products, as well as examine possibilities for creating meaning in the generation of a differentiated personal narrative for an artist / band.

\section{Keywords}

Music video, visual album, contemporary visual aesthetics (Source: Unesco Thesaurus). 


\section{0 álbum visual como nova forma promocional da indústria da música: o caso de Let England Shake, de PJ Harvey e Seamus Murphy}

\section{Resumo}

O novo modelo de negócio para a indústria fonográfica começa a se basear nos conteúdos digitais. Vários autores têm estudado e afirmam que a indústria musical experimenta uma virada em direção ao conteúdo audiovisual. Isso está delimitado numa nova etapa de estética audiovisual caracterizada pela transmidialidade e pela convergência de meios ao redor dos formatos audiovisuais complexos. O álbum visual, como conceito formado por videoclipes de todas as músicas de um disco, consolida-se como um novo formato promocional musical, híbrido entre cinema e vídeo musical. Neste trabalho, será realizada uma análise do álbum visual Let England Shake (PJ Harvey e Seamus Murphy, 2011), com uns critérios que tentam buscar motivos visuais que gerem continuidade, unidade temática e narrativa para demonstrar sua intensa coerência com o álbum musical precedente. Pretende-se definir o álbum visual e começar a delimitá-lo ante outros tipos de produtos audiovisuais, bem como examinar suas possibilidades de criação de sentido na geração de uma narrativa pessoal diferenciada para um artista/banda.

\section{Palavras-chave}

Videoclipe, álbum visual, estética audiovisual contemporânea (Fonte: Tesauro da Unesco). 


\section{Marco teórico}

\section{El videoclip y la música insertos en un ecosistema audiovisual y de convergencia de medios}

A pesar de ser uno de los formatos centrales de la renovación del audiovisual por su capacidad de adaptación a los canales de distribución digitales y de hibridación con otros formatos y propuestas, aún no se puede afirmar que exista algo así como una teoría del videoclip contemporáneo. En él se evidencian, mucho antes que en otros textos, las modificaciones que las industrias culturales sufren por los cambios en los contextos de producción y recepción. Esto lo vuelve un formato volátil, en el que se hibridan otras formas de visualización con las que la industria de la música trata de posicionar $y$ visibilizar a sus artistas.

Su naturaleza de formato de promoción musical lo ha condicionado desde una industria que se encuentra en continuo cambio y transformación: no interesada, por tanto, en su archivo o conservación. Esto se ha acentuado desde la aparición de Internet. En primer lugar, porque ofrece en sí misma muchas oportunidades de distribución en canales genéricos de video (YouTube, Vimeo... ), y, en segundo lugar, porque las experimentaciones con software vuelven muchas de sus propuestas muy volátiles.

Sin duda, es un hecho que el nuevo modelo de negocio para la industria fonográfica comienza a basarse en los contenidos digitales. Esto hace tender a lo inmaterial en los soportes y a abaratar los costes de distribución. A pesar de que se produce un consumo musical fraccionado (De Bustos y Arregocés, 2006) — pues el usuario descarga o escucha en streamingla canción que quiere escuchar y no el disco completo-, el concepto de álbum sigue teniendo cierto interés para la industria como promoción, en tanto proporciona un formato cerrado y completo con el que los artistas renuevan su aparición ante sus fans y todo el entramado comercial y mediático en otra de las etapas de su carrera. 
La mayoría de las canciones y álbumes se distribuyen digitalmente en sites como YouTube, Spotify, Soundcloud o iTunes, ya sea con la modalidad de streaming o de descarga directa mediante pago. Estos contenidos se consumen en dispositivos de muy diferente función, tamaño y características de pantalla (tableta, iPod, ordenador...), lo que modifica la experiencia del usuario respecto a ellos.

Esto se une al protagonismo de YouTube como plataforma de consumo musical, debido a su naturaleza de gran contenedor, donde conglomerados mediáticos como VEVO o WMG han articulado canales propios para distribuir a sus artistas. El salto tecnológico posibilita un modelo líquido donde prima el acceso a los contenidos (Leonhard, 2008). Winter afirma que: "Cada formación histórica de cultura musical se altera cuando las condiciones del proceso de cultura de la música o sus subprocesos (producción, distribución, percepción y uso) o su cambio de relación, se sustituyen, complementan o se inventan desde algo completamente nuevo, para lograr algo que antes no era posible" (2013, p. 266, traducción propia). ${ }^{2}$

A la proliferación de video online sobre 2005, año de nacimiento de Youtube, le siguió cierto "giro hacia el video" en la industria musical a partir de 2008 (Van Dijk, 2009, p. 41; Holt, 2011, p. 52). Aunque los artistas y las discográficas continúan produciendo primero el contenido musical y más tarde el visual como apoyo promocional, el balance está cambiando. En la industria de la música independiente, por ejemplo, crece la integración de videos conceptuales desde el estreno del trabajo musical: en el mainstream, por ejemplo, se encuentran ejemplos en los videoclips de formato largo de Lady Gaga (“Telephone", "Judas”) o de Kayne West (Runaway). Otro fenómeno es la aparición del denominado videoclip oficial, que denota la variedad a veces incognoscible de producciones visuales en torno a una canción, tanto en lo que se refiere a diversos formatos (versión MTV, video expandido, versión breve, versión completa ...) como en todo lo referido al videoclip amateur o videoclip musical de usuario (versiones de los fans).

2 Each historical formation of music culture alters when the conditions of process of music culture or their sub-processes (production, allocation, perception and use) or their relationship change, are substituted, supplemented or invented completely a new, to accomplish something that had not before been possible. 
Por otro lado, Sysomos (2009) confirma que los videoclips son la categoría más popular de YouTube, pues representan el 30,7 \% de las reproducciones. Consciente de que la experiencia del usuario requerirá diferente gestión de la distribución, la industria del entretenimiento tiende hacia la creación de contenidos en diversos formatos, que puedan ser conectados. La gestión de marcas, productos, empresas o franquicias y la generación de narrativas fragmentadas asociadas a ellos en distintos medios apuntan a la creación de estrategias globales de entretenimiento. Este engranaje cohesionado de producción es la base del negocio transmedia y permite la ampliación sin fin del negocio cultural. En el caso de la música popular, la llegada del usuario activo, junto al soporte digital, ha supuesto una transformación de las posibilidades en los ámbitos de la producción, la distribución y la recepción, que ha posicionado a su producto en una situación de accesibilidad absoluta, en una permanente liquidez. Incluso puede decirse que el video online, los videoclips subidos a YouTube, afectan los modos de creatividad musical, consumo y acceso a contenidos musicales (Cayari, 2011). Fernández et al. (2012) hablan de que nos encontramos en la era del posbroadcasting musical.

Todo esto se enmarca en una nueva etapa de estética audiovisual, un conjunto de nuevas condiciones mediales que según John Richardson y Claudia Gorbman (2013, pp. 20-31) cuenta con las siguientes características:

- Una mayor interrelación audiovisual: se tiende a un crecimiento de los formatos de hibridación audiovisual y se busca generar otras experiencias sensoriales (3D, inmersión).

- Intertextualidad e intermedialidad: la convergencia de medios, la remediación, la "representación de un medio en otro" (Bolter y Grusin, 1996, p. 339; Auslander, 2008, pp. 6-7).

- Interactividad e inmersión: el performance audiovisual actual sugiere permanentemente al usuario una respuesta interactiva y lo llama a la inmersión en las historias, en nuevas experiencias.

- Necesidad de atención a la identidad cultural, la afiliación y la espectatorialidad específica de los diferentes tipos de audiencias, así como a la forma en que las dimensiones económicas en relación con lo 
audiovisual siguen siendo una prioridad para comprender los procesos de producción y consumo cultural.

- Importancia del sonido: creciente indeterminación en los límites entre los elementos de la banda sonora y la centralidad de la voz.

Este panorama de audiovisualidad creciente dibuja un nuevo mapa donde resulta fácil que se generen nuevos procesos y fórmulas de interrelación audiovisual, gracias a procesos de intermedialidad y transmedialidad. De hecho, este mapa general se ha definido como de convergencia audiovisual, "donde el video puede servir a un variado rango de funciones por estar menos limitado que la música en televisión y por ejemplo puede circular más ampliamente por los espacios de los medios”3 (Holt, 2011, p. 52, traducción propia).

De alguna manera estos fenómenos difuminan los límites entre los medios o materiales de expresión audiovisuales, suponen la consolidación de una tendencia de convergencia entre los medios y confirman la aplicabilidad en la industria musical de los conceptos de transmedialidad y crossmedia como continuadores de la serialidad narrativa televisiva, aunque expandida a todos los canales que se entienden en el universo mediático digital. Algunos teóricos perciben en esta integración de contenidos visuales con los musicales una exigencia creciente por agregar valor y enriquecer la experiencia del usuario de la música. Se exploran así nuevas fórmulas y herramientas de comunicación con el fan y se experimenta con estrategias para gestionar la personalidad pública visual de cantantes y bandas. Además, otras respuestas comienzan a percibirse en la apertura de la industria musical en su convergencia con las tecnologías de la comunicación: el concierto online (online concert experience), el concierto extraordinario (extraordinary concert event) y el videoblog, las webs de streaming multiplataforma, el surgimiento de dispositivos que priman el acceso, los códigos de descarga, la integración de tecnologías de streaming y geolocalización, y las redes sociales especializadas (Holt, 2012; Woomedia, 2014). Todas estas novedades

3 “[... $]$ video can serve a broader range of functions because it is less limited to a music show on TV, for instance, but can wider circulation across media spaces".

112 El álbum visual como nueva forma promocional de la industria de la música: ... - Ana María Sedeño-Valdellós 
responden a la necesidad creciente del artista de construir más vínculos con el público y de ampliar las vías para personalizar la experiencia del fan.

\section{El álbum visual: definición y características}

La visualidad en la música popular ha tomado muchas formas y a lo largo de su historia se ha inspirado en las innovaciones audiovisuales. Primero con el cine musical sobre rock en los cincuenta, después con la inserción de actuaciones en los talk-shows televisivos y más tarde con la generación de un formato, el videoclip, base de contenido de programas específicos. En este tipo de producto audiovisual publicitario generado por la industria se concentraron modos de creación audiovisual como el cine, el video experimental y la representación musical televisiva, lo que ha implicado una dificultad para su estudio y especificidad como mensaje audiovisual.

El videoclip contemporáneo, coherente con las peculiaridades de un nuevo ecosistema mediático (Scolari, 2015), se ha basado en esa necesidad de la industria musical por integrar sus productos en un contexto multimediático. Carol Vernallis (2013) incide en que existe esta segunda etapa de la estética videoclip, en la que su narrativa y discurso se han visto modificados por la incorporación de macrosites (Vimeo, YouTube), la irrupción del fan video y la llegada del videoclip interactivo, el video musical móvil, el web-based o el videoclip transmedia. Esto está modificando la manera de entender el formato y su ubicación en el espectro de géneros audiovisuales (Sedeño, 2012, 2014). El videoclip está adaptándose tan certeramente a las nuevas narrativas digitales e interactivas, que puede hablarse de una nueva era de la narrativa en el clip, que consigue visualizar la música y musicalizar la visión (Korsgaard, 2013).

A pesar de la importancia del contenido digital e Internet, sigue existiendo en torno al videoclip musical y, ahora, el álbum visual, un nexo profundo entre todas las formas de arte visual, videoarte, fotografía, cine y televisión, que siguen manifestándose como fenómenos solo explicables y analizables desde una mezcla de todos ellos. Como el videoclip, un álbum visual es un híbrido entre cine y video: como video musical promociona 
un álbum, y como mensaje audiovisual transporta influencias estéticas de numerosos formatos anteriores. Tras el álbum visual se encuentra otro relevante cambio en la industria, que, además de su adaptación a un nuevo sistema de interrelación de productos culturales, se ha concentrado en aumentar los beneficios con formatos reducidos, los singles, intentando darles el máximo de formatos posibles para su distribución.

Harrison (2014) proporciona tres características para este formato de promoción. En primer lugar, existe una relación directa entre el álbum visual y el sonoro. Esto no significa que el álbum visual esté limitado por las canciones del álbum de audio, solo que se materializa en una conexión entre dos productos, que a veces pueden haber sido creados diacrónicamente (Beyoncé, por ejemplo) o sincrónicamente, como el ODDSAC de Animal Collective.

Una segunda característica supone su transformación constante, como es genuino del formato videoclip desde su nacimiento. La variedad de las versiones de video puede comprobarse en las denominaciones y variedad de formatos (versión MTV, versión completa... ). Fabian Holt llama videocanción cinemática (cinematic song-video) a un formato que está revolucionando los límites de MTV: se trata de videos como Telephone de Lady Gaga, construido con una sensibilidad crossmedia, que contiene influencias de películas de ciencia ficción, videojuegos e instalaciones (Holt, 2011, p. 52), sin dejar atrás la clásica narrativa fílmica.

Como tercera característica del álbum visual, la autora apunta la posibilidad de elaborar dos formatos: puede configurarse como un track audiovisual por cada track de audio del disco (Beyoncé, Let England Shake) o desplegarse en continuidad en relación directa con el álbum de audio (ODDSAC, de Animal Collective.).

Con todo esto podría proporcionarse una definición de álbum visual como "un producto audiovisual que tiene una relación directa con la música de un álbum del mismo artista. La duración del álbum es mayor que la duración estándar de 3-5 minutos, y están presentes fuertes relaciones 
textuales y visuales para crear continuidad en todo el álbum" (Harrison, 2014, pp. 16-17). ${ }^{4}$

\section{Precedentes: otros álbumes visuales}

El álbum visual no ha sido habitual en la historia del pop, pero pueden citarse como excepciones al grupo Sonic Youth, con sus videos de las canciones de Goo, que no guardaban, sin embargo, ninguna unidad creativa o temática, y a Super Furry Animals, con su DVD Rings Around The World (2001).

Más recientemente, el caso de la banda de rock experimental Animal Collective con su ODDSAC (2010) sigue este camino. Gestado durante un periodo de producción de cuatro años, el álbum fue presentado en el festival de Sundance. Las imágenes y la música fueron creadas paralelamente desde una concepción holística que desbordaba la idea de álbum visual y videoclip.

Otro ejemplo de álbum visual es el disco My Beautiful Dark Twisted Fantasy de Kayne West: Runaway es un videoclip expandido de ocho de las trece canciones del disco. Concebido como material promocional, se ha editado en variados formatos de duración. Existen, en la actualidad, diversos formatos audiovisuales de promoción para la música popular en forma de teasers, comerciales y cortometrajes, y no faltan los intentos de hibridación entre estas categorías. El grupo Dirty Projectors presentó su filme corto experimental Hi Custodian en el que suenan algunas canciones de Swing Lo Magellan. Este caso emparentado con el de Kayne West resulta mucho menos conocido pero da cuenta del interés de la música independiente por buscar formatos de visualización musical.

El grupo islandés Sigur Rós, por otra parte, proporcionó a una docena de realizadores la misma cantidad de dinero para generar doce videos de las doce canciones del álbum Valtari, en lo que se denominó el Valtari Mystery

4 “[... $]$ a visual album is an audio-visual product that has a direct relationship with the music from a corresponding audio album by the same artist (s). Its album length is more than the standard music video lenght of 3-5 minutes, and strong visual and textual relations are present to form continuity throughtout the whole album" (Harrison, 2014, pp. 16-17). 
Film Experiment (2012). Las variadas formas de concurso con la participación del fan o receptor son cada vez más empleadas en la industria musical.

El grupo español Love of Lesbian presenta un caso distinto, pues se ha decantado por la construcción de una historia transvideo: sin optar por un formato completamente narrativo, la sucesión de postales emotivas (dirigidas por Marta Puig) de las diferentes fases de la relación amorosa de una joven pareja sirve de hilo conductor para la creación de una forma de narrativa minimalista, en la que solo se mantienen personajes y vestuario, mientras se modifican temporalidades y escenografías. En su álbum Biophilia, la cantante islandesa Björk colaboró con científicos, músicos y desarrolladores de aplicaciones para crear una visualización en forma de apps para cada track de las relaciones entre las estructuras musicales y los fenómenos naturales (Brandon, 2011).

Sin embargo, es el último álbum de Beyoncé (Beyoncé, 2013) el que parece acaparar el sentido último de la denominación de álbum visual en tanto su concepción fue sincrónica y su lanzamiento planeado como un único acontecimiento con un objetivo sorpresivo para la industria musical: la artista planeó y produjo este trabajo obviando teasers y demás formatos de anticipación para buscar un lanzamiento único. El proyecto ha provocado múltiples especulaciones sobre sus condiciones de producción y realización.

\section{Metodología}

Como apunta Mundy (1999), el videoclip supone una continuación de la relación establecida entre la música popular y la imagen por el conglomerado de industrias culturales a lo largo del siglo XX. Aunque existe escasa tradición académica de análisis del videoclip desde esta perspectiva, es conveniente no dejar de lado las complejas relaciones en el plano industrial de estos textos con un doble origen, el visual y el sonoro. Es decir, por un lado, videoclip y álbum visual remiten a una tradición narrativa en la que el cine, el videoarte, la programación televisiva, etc., han conformado unas fórmulas válidas de narrativa y significación. Por otro, remiten también a la tradición del ámbito musical. Goodwin fue el primero que intentó aplicar las ideas musicológicas al análisis del videoclip (Goodwin, 1992, pp. 49-50), 
intentando alejar la tendencia a aplicar enfoques narrativos provenientes de la teoría cinematográfica al discurso del videoclip. De este modo, por ejemplo, si para autores como Kinder (1984) el hecho de la mirada a cámara rompe con la ilusión ficcional que se integra en toda narración, para Goodwin (1992, p. 74) se trata de una integración de la expresión de la música popular en el discurso visual.

También Simon Frith critica buscar el origen y especificidad del videoclip en la narrativa cinematográfica, contraponiendo dos formas claras, la de la música de cine y la del videoclip. En la primera, "las imágenes determinan la música (y en la mayoría de los casos las precede) y el realizador trabaja para una secuencia de imágenes, cuya narrativa es su tarea mejorar y comentar". Sin embargo, en los videos "la música determina la imagen y por lo tanto el creador del video trabaja con una secuencia de sonidos, para crear una narrativa de la actuación” (Frith, 1988, p. 219).

El álbum visual debe ser entendido como un formato más en el proceso de búsqueda de una narrativa para la música popular. Este proceso es necesario, además, para comprender la significación del álbum visual como evolución del videoclip musical. En esa línea se encuentra la idea de texto estrella (star-text) de Goodwin (1992, p. 100). El autor afirma que la industria musical persigue la creación de una narrativa en torno a todo artista (solista o grupo) y que esto se compone con la suma de una serie de técnicas y medios alrededor del producto musical y sus creadores. Se trata de un concepto genérico diferenciador que supone una mezcla de ficción, narrativa e identidad. En este objetivo, el videoclip ha tenido un papel importante como creador de sentido, junto a elementos como las portadas del disco, la puesta en escena del concierto, las entrevistas, etc. A su vez, este conjunto de ideas e imaginario en torno al artista influye sobre la recepción del discurso de cada videoclip o del conjunto de videoclips de un artista, en un bucle continuo de creación de sentido. Este mecanismo permite que más de una identidad del artista conviva dentro del mismo texto: la importancia que algunos artistas como Madonna o David Bowie han depositado en el videoclip como gestor de su personalidad frente a sus públicos asílo demuestra. Otra prueba de ello la introduce Frith cuando afirma que "las dis- 
cográficas computan el éxito de los videoclips en función de los procesos de creación de estrella, no en cuanto a la venta de singles" (1988, p. 215).

Existen otros factores de definición del texto estrella, como los provenientes de los géneros musicales y sus universos de puesta en escena. El rap, el rock, el heavy, todos los géneros musicales básicos de la música popular buscan una puesta en escena de base que tienden a consolidar a través de los diferentes "textos" con los que se visibiliza o presenta a sus fans.

Recientemente, Cara Harrison (2014) ha estudiado detalladamente el caso del álbum epónimo de Beyoncé. Aquí se seguirá su estructura metodológica: la autora propone la búsqueda de motivos visuales y códigos de imagen que aporten continuidad, que definan una temática y una narrativa: "el álbum visual crea continuidad a través del uso de leitmotivs visuales, que aluden a las narrativas ficcionales y personales" (Harrison, 2014, p. II, traducción propia). ${ }^{5}$

De esta manera, se asume que elálbum visual debe tener mecanismos para dar unidad a los diferentes videos que lo componen. Estos pueden ser motivos repetitivos (motivos temáticos, imágenes similares, localizaciones o personajes) y de tipo estructural, rasgos audiovisuales recurrentes. El motivo es definido como "un tema [...] cuyo propósito es representar o simbolizar una persona, objeto, lugar, idea, estado de la mente, fuerza sobrenatural o cualquier otro ingrediente en un trabajo dramático" (Chandler y Munday, 2011). Se considera, con Lessing, el motivo visual como un "momento pregnante", caracterizado por una inmovilidad de la acción (Balló, 2000, p. 17). Es decir, el motivo no refiere a una narrativa clásica de causa-efecto sino a otra narratividad, al modo en que la pintura crea escenas "impregnadas de tiempo", al modo de tableaux vivants.

Estos leitmotivs construyen determinados conceptos generales que apelan a una temática y una narrativa personal o diferenciada para el conjunto de clips.

5 “ (... the visual album creates continuity through the use of visual leitmotifs, which allude to earlier fictional and personal narratives” (Harrison, 2014, p. II). 
Los temas que forman este disco son los siguientes:

- Let England Shake

- The Last Living Rose

- The Glorious Land

- The Words that Maketh Murder

- $\quad$ All and Everyone

- $\quad$ On Battle Ship Hill

- $\quad$ England

- In the Dark Places

- Bitter Branches

- Hanging in the Wire

- Written on Forehead

- The Colour of the Earth

\section{Análisis del álbum visual Let England Shake (PJ Harvey \& Seamus Murphy, 2011)}

Let England Shake Video Project del disco Let England Shake de Polly Jean Harvey (PJ Harvey) es una serie de doce clips dirigidos por Seamus Murphy que acompañan al octavo álbum de estudio de la artista británica.

La historia del disco comienza cuando la cantante visita la exhibición A Darkness Visible, de Seamus Murphy, una colección de fotografías tomadas desde 1994 a 2006 y que muestra los efectos del régimen talibán y la guerra civil en Afganistán. Parece que queda impresionada por ciertos paralelismos con su experiencia en ese país, de donde acaba de regresar de un viaje en búsqueda de inspiración para las letras de su nuevo disco. Inmediatamente solicita al fotógrafo su colaboración para que tome las fotos promocionales de Let England Shake y para que ruede un documental sobre el proceso de grabación. Tras un tiempo de trabajo, los dos artistas decidieron que el formato final constara de doce filmes que aparecerían individualmente 
durante algunos meses; estos videos constituyen uno de los mejores intentos de ampliar la temática y el mensaje del disco (Pons, 2012).

Procedamos al análisis de los motivos visuales y códigos de imagen que nos permitan estudiar los rasgos de continuidad, temática y narrativa en este álbum.

En primer lugar, podríamos hablar de cierto formato presente en todos los clips. La existencia de una intro no musical compuesta por una escena con sonido directo resulta un aspecto destacable. Esta se encuentra formada por imágenes según tres modalidades: 1) imágenes cuasidocumentales de interiores (un museo), 2) un performance de la artista en un entorno doméstico, con una estética amateur y sonido directo, y 3 ) un personaje que recita parte de la letra de la canción posterior.

En la primera de las soluciones, siempre se produce un cierre del video, relacionado con la introducción (normalmente, el mismo plano); en la segunda (lo que suele traducirse en un videoclip de mayor presencia performance) se recurre a la misma alternativa (es decir, la repetición del momento de actuación de la artista concurre al principio y al cierre del video), y en la tercera (en la mayoría de los casos, repetida en cinco de ellos), no se retorna al personaje, excepto en el primer video, que comparte título con el álbum.

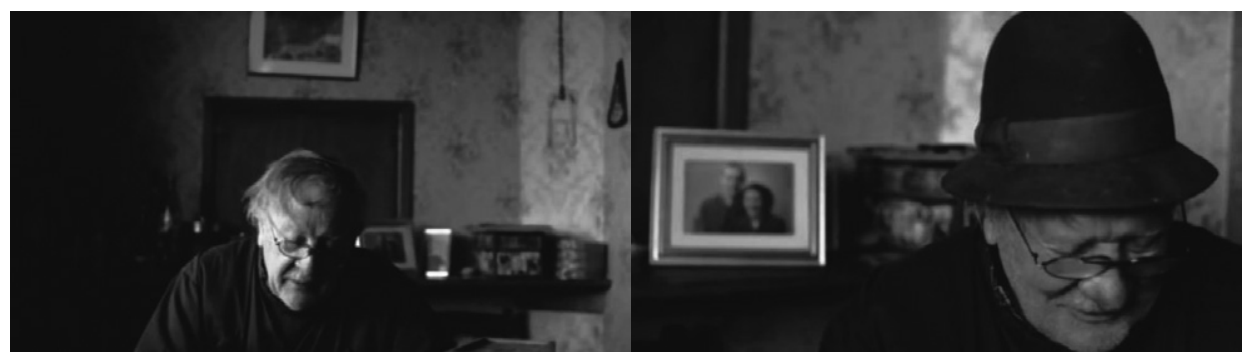

Intro de "Let England Shake".

Final de "Let England Shake".

En el segundo de los recursos, son destacables los videos "The Glorious Land" y "The Words that Maketh Murder". 


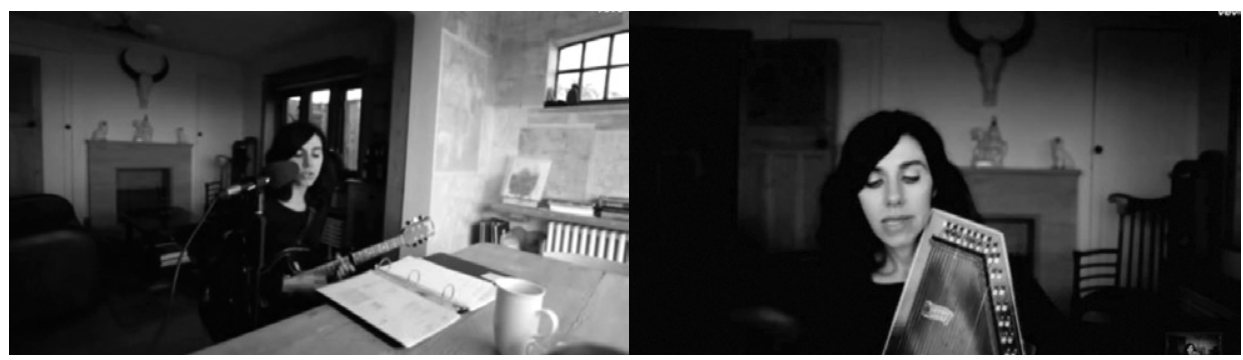

Frame de "The Glorious Land".

Frame de "The Words that Maketh Murder".

El último de los videoclips de la serie, “The Colour of the Earth”, revisa esta estructura de presentación, aunque a través de la figura en plano americano de la artista y su grupo cantando a capela. Esta es la única ocasión en que se concede al espectador la visión del conjunto de músicos que ha trabajado con la artista en los últimos años.

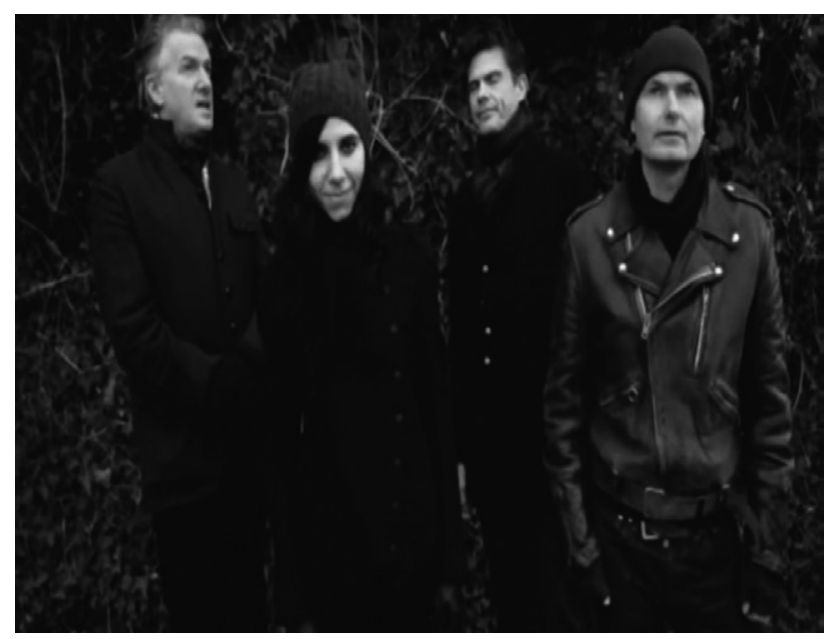

Frame de "The Colour of the Earth".

También los videoclips “The Last Living Rose", “The Words that Maketh Murder" y "In the Dark Places” guardan este formato.

Este especial proceso de formateado de los clips ocurre en todos los casos, excepto en uno: el de "All and Everyone", el track número cinco, y casi central, del disco.

Por otro lado se encuentra la fotografía. La estética de video digital HD proporciona a las imágenes sombrías de interiores y de exteriores 


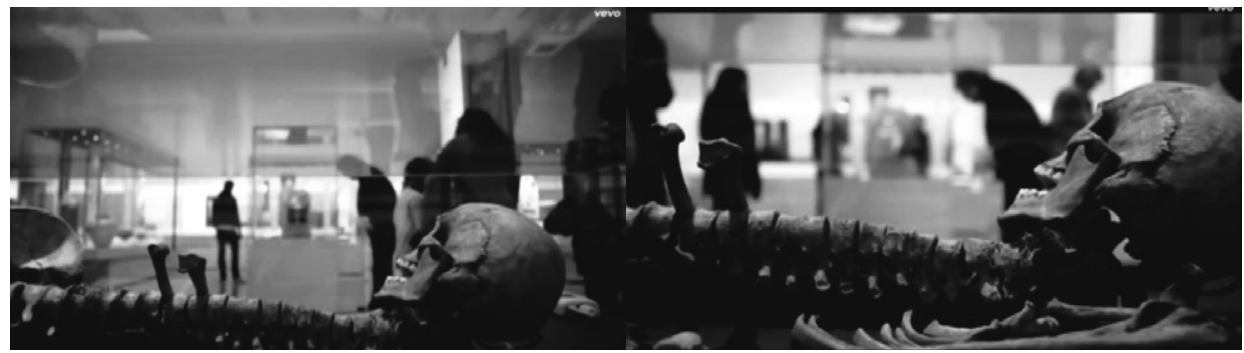

Intro de "The Last Living Rose".

Final de "The Last Living Rose".

nublados una unidad interesante, que se suma al material fotográfico anterior de Murphy y a grabaciones caseras de la artista. Estos tres componentes son otros elementos cohesivos del texto analizado. En primer lugar, esta insistencia en lo sombrío en el interior y el exterior nublado puede comprobarse en todos los clips, pero especialmente en "Hanging on the Wire" y "All and Everyone".

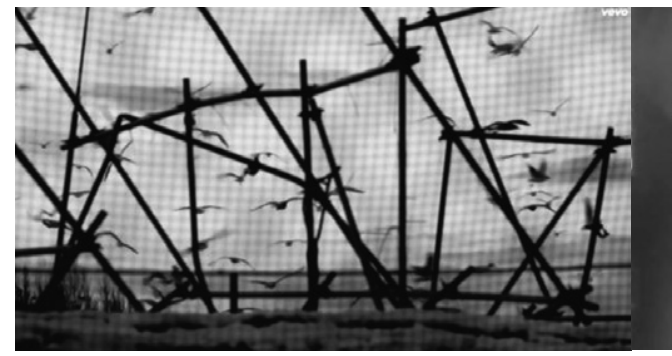

Frame de "Hanging on the Wire".

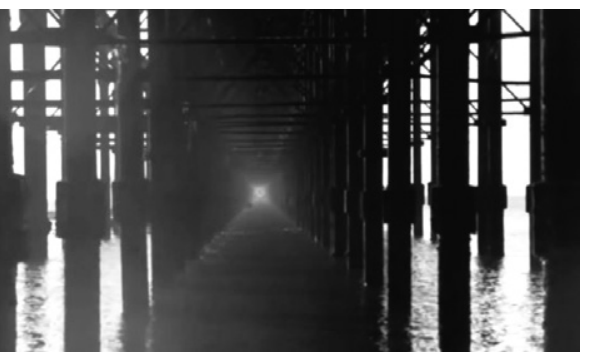

Frame de "All and Everyone".

Por otro lado, es subrayable cómo las decisiones de realización suponen otro elemento cohesivo: se encuentra una planificación en detalle y una filmación en plano general, es decir, soluciones visuales extremas en la escala y que alejan la realización audiovisual de su centro en los personajes o en tramas narrativas clásicas.

Los planos detalle o carentes de una referencia espacial anterior en forma de plano general o establishing shot generan un discurso poblado de paisajes vacíos de personajes o elementos cinéticos. Estos construyen un discurso visual basado en la suma de planos con influencia de la representación fotográfica, estática, fija, variadamente descriptiva y una 
representación temporal suspendida, que refiere a una especie de tiempo muerto de las imágenes.

Esto se suma a veces a una duración alargada de las unidades plano, como en el caso de "All and Everyone": este clip posee una duración media de plano de 11,34 (11 planos en seis minutos y dos segundos), con un plano en travelling de un minuto y 40 segundos. Es decir, en cuanto a duración de las unidades plano, "All and Everyone" se desarrolla entre dos extremos: desde planos de 8,39 segundos hasta el mencionado anteriormente. En cualquiera de los casos, está alejado de la edición rápida y rítmica que caracteriza a los videoclips clásicos.

Por otro lado, los planos secuencia (o de larga duración), de cámara fija, medios o de encuadre entero aportan un cierto toque documental, acorde con la especialidad de fotografía bélica del autor.

En referencia a la guerra de Afganistán destaca el clip "Written on the Forehead”, donde se contraponen el color y el blanco y negro, asignando al primero imágenes de procedencia de interiores cotidianos, sin referencias personales y muy descriptivas (en el metro, en el bus, en escaleras...), y al segundo imágenes estáticas (fotografías) de alto contenido violento, procedentes de lugares en conflicto. El efecto de contraste que tiene la yuxtaposición de estas series de imágenes conduce al espectador a preguntarse por su relación, a buscar un sentido en el montaje alternado.

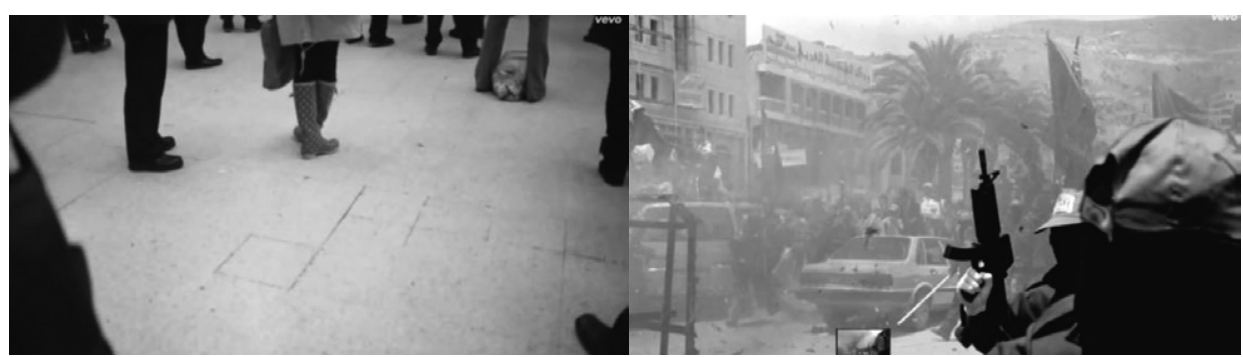

Frame de "Written on the Forehead".

Frame de "Written on the Forehead".

En otro orden de cosas, en lo que respecta a la narrativa y la temática del disco, Let England Shake continúa la tradición artística inglesa en torno 
al paisaje (árboles, jardines, riberas): los pequeños detalles en planos de larga duración o en planos estáticos a modo de postal (como en "England" u "On Battleship Hill") dibujan una aproximación bucólica y de reminiscencias románticas a esta temática.

Algunos de los motivos visuales mencionados en torno a este aspecto se encuentran en toda la tradición visual y fílmica inglesa. El movimiento romántico supuso en Gran Bretaña una revalorización de estos motivos a través de la pintura y la poesía: ambas configuraron una metáfora del paisaje como paisaje espiritual. La teoría del sobrenaturalismo natural describe la capacidad del ser humano para fundirse con ciertas ideas del absoluto a través de la representación de la naturaleza. En ella, se trasciende la representación realista y se busca la verdad espiritual, símbolo del deambular histórico del ser humano y de su incapacidad para dominar cualquier elemento de la naturaleza. Esta visión esencialista y sublime de los ideales de la naturaleza en el romanticismo fue desarrollada por artistas, poetas y pintores como Wordsworth, Coleridge y Shelley, y por teóricos como John Ruskin, famoso crítico y sociólogo de la época, que encontró en la pintura de Turner el ejemplo de una visión moralista del paisaje romántico: "Y el objetivo del gran paisajista inventivo debe consistir en dar la verdad mucho más elevada y profunda de la visión espiritual, y no la de los hechos físicos y llegar a una representación que $[\ldots]$ sea capaz de producir en el espíritu del espectador lejano precisamente la impresión que la realidad había producido" (1996, pp. 247-248).

La insistencia en el paisaje y lo pastoril entronca el trabajo de PJ Harvey y Seamus Murphy con toda una tradición inglesa de rechazo de lo urbano después de la Revolución Industrial (no puede olvidarse que fue Inglaterra el primer país en experimentar sus consecuencias) y de reivindicación de los valores rurales y tradicionales. Sus precedentes son William Blake, William Morris, Geoffrey Chaucer y William Shakespeare.

También podrían citarse algunos cineastas y sus obras. Michael Powell y Emeric Pressburger rodaron el cortometraje A Canterbury Tale (1949) y Ken Russell Elgar: Portrait of a composer (1962). Toda esta producción se 
encuentra dominada por la exaltación de la mentalidad romántica y el protagonismo de la evocación de un pasado mejor a través de la campiña inglesa y sus gentes. También Derek Jarman (Jubilee, The Last of England) compone un cuadro de su país en el que el paisaje tiene un carácter moral describiendo las situaciones de declive y caos en las que desarrolló su trabajo desde finales de los setenta y los ochenta (durante el gobierno de Margaret Tatcher), una época marcada por el desempleo generalizado, la crisis y los ideales de la nueva derecha que convertían en un infierno la existencia de la mayoría de los británicos.

\begin{abstract}
[...] así, el mito de lo rural incidió en evocaciones del carácter nacional. El carácter del entorno campirano se asentó sobre una base idealizada de principios -como el balance, el tradicionalismo, el pacifismo, el bien comunal, la caballerosidad y la espiritualidad- que delinearon el carácter inglés. Los simpatizantes de lo mítico rural han visto en el campo una figura de distanciamiento con la sociedad tecnologizada y eso los ha hecho evocar el pasado, añorando los prados extintos por la irrupción de la innovación industrial (Rodríguez, 2011, p. 159).
\end{abstract}

La evocación histórica (colonial) y de un pasado repleto de incursiones bélicas (Primera Guerra Mundial, especialmente) del álbum es otro motivo constante, que se encuentra en la letra de algunos temas, como "The Words that Maketh Murder", en el que se escucha "I've seen flies swarming everyone, soldiers fell like lumps of meat". Esta frase es una clara referencia a las condiciones de vida de los soldados en la batalla de Galípoli (Turquía), una de las derrotas más terribles del ejército inglés en la Primera Guerra Mundial. La conciencia sobre la historia e identidad como país y su referencia constante han fundamentado numerosas obras artísticas, sumergidas en un sentimiento de profunda nostalgia. La insistencia en una recuperación y revalorización de formas de vida antiguas, inscritas en épocas gloriosas del país, está detrás de las obras de Terence Davies (Of Time and the City), Shane Meadows y, de nuevo, Derek Jarman (War Requiem).

Otras son las referencias a la tradición fílmica inglesa. Por ejemplo, $O$ Dreamland (1953), donde el representante del Free Cinema Lindsay Anderson revaloriza el trabajo del documentalista Humphrey Jennings. Este cortometraje fue filmado en el parque de atracciones de Margate, en Kent, 
y en él se registran las actividades de los paseantes y todas las curiosidades que los rodean. La pieza "Let England Shake", el primer track, ofrece claras reminiscencias de este imaginario circense propio de las décadas centrales de la Inglaterra del siglo XX.

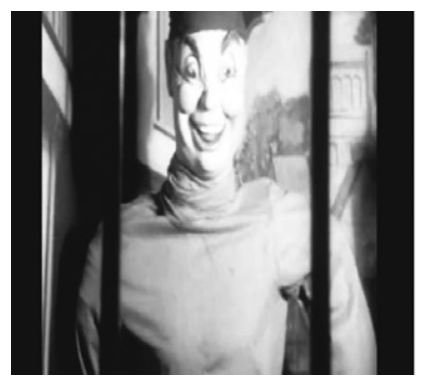

0 Dreamland.

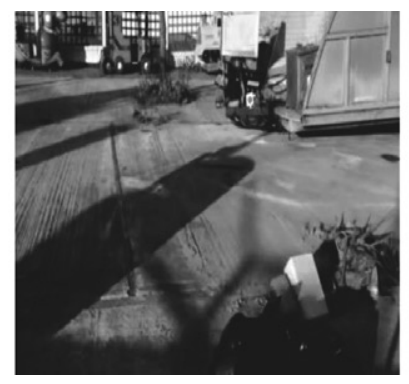

"Let England Shake".

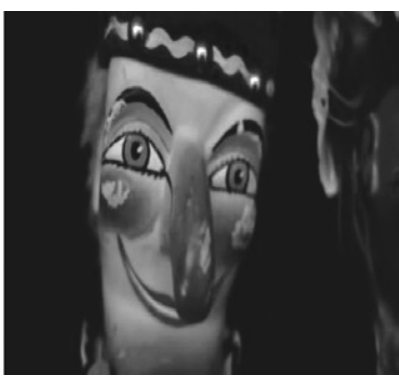

"Let England Shake".

En definitiva, parece ser Inglaterra, y algunos de sus motivos y temáticas tradicionales, el asunto que se encuentra detrás de las imágenes de este álbum visual de PJ Harvey y Seamus Murphy. De hecho, el propio Seamus Murphy confirma:

Quería mirar el enigma de Inglaterra, su mentalidad de isla y su complicada relación con su pasado. La Inglaterra contemporánea surge de una historia de aventuras coloniales, ambiciones militares, destreza industrial y una jerarquía rígida. Ahora también se define por su menguante poder y su papel en la geopolítica moderna. $Y$ puede ser un lugar gratificantemente extraño (2011, traducción propia). ${ }^{6}$

\section{Conclusiones}

Uno de los mayores problemas del videoclip seguramente es el de su estudio como formato o género comunicativo. Su alta heterogeneidad y la multitud de facetas comunicacionales y creativas que reúne dificultan la reflexión en torno a él, su cierre como campo con un abordamiento metodológico. La dificultad aumenta cuando se considera la extrema versatilidad de las ver-

6 "I wanted to look at the enigma of England, its island mentality and complicated relationship with its past. Contemporary England springs from a history of colonial adventures, military ambitions, industrial prowess and a rigid hierarchy. Now it is also defined by its waning power and role in modern geopolitics. And it can be a gratifyingly odd place" (Murphy, 2011). 
siones e hibridaciones mediáticas surgidas en esta nueva etapa de la industria musical, como en el caso del álbum visual.

Este texto ha tratado de analizar el álbum visual como nueva modalidad de presentación y promoción de la industria discográfica, que toma al videoclip como punto inicial empleando las claves de serialidad y aprovecha el nuevo ecosistema mediático basado en la transmedialidad y la convergencia de canales y códigos en lo digital.

Se han utilizado para ello los criterios de coherencia, temática y narrativa (sugeridos por Harrison, 2014), a través del estudio de sus motivos visuales, su temática y características como propuesta narrativa.

Cada videoclip contenido en Let England Shake incorpora una mezcla de fotografía y video que documenta los temas del álbum a la manera de la fotografía de reportaje, para documentar el universo personal de la artista durante su viaje a Afganistán y su vuelta a las islas británicas.

Se ha explorado cómo los motivos visuales aluden a una temática que se conforma como totalidad en Let England Shake: la relación de Inglaterra con su pasado y su presente a través de su participación en la guerra de Afganistán. Las alusiones son múltiples y se concretan sobre todo en la visión del paisaje, de alta raigambre en la tradición artística inglesa desde el romanticismo.

Let England Shake contiene las características que se han definido para un álbum visual. Por un lado, puede localizarse un importante número de rasgos visuales que aportan coherencia y continuidad a lo largo de todos los clips. En primer lugar, todos los clips tienen una intro no musical. En la mayoría de los casos eso se corresponde con un cierre o conclusión en paralelo. Es decir, existe una relación explícita al mismo espacio o a los personajes con los que se abría el video (figuras recitadoras, árboles). En segundo lugar, existe una tendencia al plano estático: ya sea en material evidentemente grabado por Murphy para el video o procedente de un registro documental anterior (en formato videográfico o fotográfico), existe una 
explícita tendencia a los encuadres con nulo o escaso movimiento, a modo de cuadros o tableaux vivants.

En cuanto a la narración, podemos apuntar a la necesidad de construcción de una narrativa personal: en repetidas ocasiones, a través de planos medios de grabación doméstica, la artista inserta su presencia física, que resulta disruptiva sobre las imágenes conceptuales y evita asíla excesiva desconexión del objetivo promocional que tiene todo videoclip. La visualización del performance de Harvey (con su componente de autenticidad de este tipo de clip) apenas alcanza una duración de un par de minutos, si se suman todas las ocasiones en que aparece, pero supone un elemento básico de unidad del clip: refiere el discurso visual a una línea de implicación emocional y conceptualización artística.

La significación en torno a motivos visuales nos lleva a subrayar de nuevo la importancia del paisaje rural, el bosque, el jardín, por un lado, y el mar, las zonas costeras y las olas rompientes, por el otro. En interiores, destaca la insistencia en la creación de escenas a modo de cuadros para la descripción de paisajes humanos con alta carga decadente (salas de juego, salas de baile de salón...), donde personajes anónimos, en su mayoría maduros o mayores, realizan acciones aburridas, rutinarias, normalmente en soledad. Estos pasajes y paisajes recurrentes - exteriores e interiores- pueblan la mayoría de las imágenes del álbum analizado.

Let England Shake y su naturaleza de álbum visual continúa el camino de convergencia de la industria musical con los medios audiovisuales, a través de una plena conciencia de la necesidad de coherencia conceptual para aportar valor al texto-estrella PJ Harvey. Además, supone un ejemplo de cómo la industria de la música se adapta a las posibilidades de la red como medio. En este trabajo se hermanan las capacidades de lo visual para dar forma a una narrativa personal (la del artista y su poética) con una reflexión sobre el presente de Gran Bretaña tras su participación en la guerra de Afganistán, tema que inspiró a la cantante durante la etapa de creación. Las piezas-video han sido planteadas de forma coherente y se han liberado organizadamente en diferentes plataformas con un objetivo específico 
de apoyar el discurso del disco: ello se concreta en la utilización de motivos visuales como paisajes y gentes, que sirven como fondo emocional y escenográfico y resultan variaciones de las múltiples tonalidades emotivas en torno a este tema.

El álbum visual parece convertirse en otra línea con la que la industria musical integra las posibilidades de generación de discursos en torno a un producto (álbum musical) y/o artista (músico en solitario o banda): supone un novedoso fenómeno de intercambio de la cultura visual contemporánea, que ensaya otra fórmula de interconexión entre valor comercial del producto y creación de un storytelling mediático fragmentado en diferentes piezas estratégicamente canalizadas. Esta nueva solución comercial solo comienza su camino con los ejemplos de Beyoncé (2013) o Let England Shake (2011), pero puede esperarse que estos trabajos de abordaje globalizador se repitan y aumenten su calidad en los próximos años.

\section{Referencias}

Auslander, P. (2008). Liveness: Performance in a mediatized culture. Londres: Routledge.

Balló, J. (2000). Imágenes del silencio: los motivos visuales en el cine. Barcelona: Anagrama.

Bolter, J. D. \& Grusin, R. (2000). Remediation: Understanding New Media. Cambridge: MIT Press.

Brandon (2011). Björk talks Biophilia. Stereogum. Recuperado el 10 de marzo de 2014, de http://www.stereogum.com/744502/stereogum-qa-bjork-talksbiophilia/franchises/interview/attachment/ bjork-crystalline-3/

Cayari, C. (2011). The YouTube effect: How YouTube has provided new ways to consume, create, and share music. International Journal of Education \& the Arts, 12(6). Recuperado el 3 de mayo de 2015, de: http://www.ijea.org/v12n6/ 
Chandler, D. y Munday, R. (2011). Motif. A dictionary of media and Communication.

Cohen, J. (2008). Dustin McLean reinvents the music video. Tubefilter, 7 de octubre. Recuperado el 15 de abril de 2015, de http//newstubefilter.tv/2008/10/07dustin-mclean-reinvents-the-music-video

Fernández, J. L., García, R., Hartridge, M. V., Lucente Vargas, J. E. y Núñez, M. L. (2012). Música e internet, ¿del delivery a la producción? En Carlon, M. y Scolari, C. A. (eds.), Colabor_arte. Medios y artes en la era de la produccion colaborativa (pp.91-110). Buenos Aires: La Crujía.

Frith, S. (1988). Music for pleasure. Essays in the sociology of pop. Cambridge: Cambridge University Press.

Goodwin, A. (1992). Dancing in the distraction factory: Music television and popular culture. Londres: Routledge.

Harrison, C. (2014). The visual album as a hybrid art-form: A case study of traditional, personal, and allusive narratives in Beyoncé. Tesis de maestría para el grado de Cultura Visual. Lund: Department of Arts and Cultural Sciences, Lunds University.

Holt, F. (2011). Is music becoming more visual? Online video content in music industry. Visual Studies, 26(1), 50-61. doi: 10.1080/1472586X.2011.548489

Korsgaard, M. B. (2013). Music video transformed. En Richardson, J. Gorbamn, C. \& Vernallis, C, The Oxford handbook of new aesthetics. Oxford: Oxford University Press.

Leavitt, A. (2010). The transmedia potential of music video, Part 1. The Band. FoE (Future of Entertainment), marzo. Recuperado el 4 de febrero de 2013, de: http://www.convergenceculture.org/weblog/2010/03/the_transmedia_potential_of_so.php 
Leonhard, G. (2008). Music 2.0. Hämeenlinna, Finlandia: Batmosphere.

Miguel de Bustos, J. C. y Arregocés, B. (2006). Industria fonográfica. Hacia un nuevo modelo de la industria musical. Telos Cuadernos de Comunicación e Innovación, 68. Recuperado el 10 de enero de 2015, de http://telos.fundaciontelefonica.com/telos/articuloperspectiva.asp@idarticulo=2\&rev=68.htm

Mundy, J. (1999). Popular music on screen. From Hollywood musical to music video. Manchester: Manchester University Press.

Murphy, S. (2011). Let England Shake: 12 short films by Seamus Murphy [DVD]. Universal Music.

Pons, J. (2012). PJ Harvey, Let England Shake video Project. Rock de Lux. Recuperado el 9 de septiembre de 2014 de http:/ /www.rockdelux.com/ audio- video/p/pj-harvey-let-england-shake-video-project.html

Richardson, J., Gorbman, C. y Vernallis, C. (2013). The Oxford handbook of new aurdiovisual aesthetics. Oxford: Oxford University Press.

Rodríguez, A. (2011). Nostalgia de la rosa: elegía y añoranza en el cine de Derek Jarman. Tesis inédita de Maestría en Estudios Cinematográficos. Guadalajara: Universidad de Guadalajara.

Ruskin, J. (1996). Sobre Turner. México: Universidad Nacional Autónoma de México.

Sysomos, Inc. (2009). A look inside online video engagement-Part I. Recuperado el 22 de noviembre de 2014 de http://www.sysomos.com/ reports/video/

Sedeño, A. (2012). Producción social de videoclip. Fenómeno fandom y video musical en crisis. Comunicación, 10(11), 1224-1235. 
Sedeño, A. (2014). Contenido de video online para la industria musical: nuevas tedencias de videoclip musical y videoclip musical interactivo. En Sierra, J. y Rodrigues, D. (coords.), Contenidos digitales en la era de la sociedad conectada (pp.345-360). Madrid: Fragua.

Scolari, C. (2015). Ecología de los medios. Barcelona: Gedisa.

Serritt, L. (2012). The lack of narrative as narrative. Transchordian, 5 de septiembre. Recuperado el 14 de enero de 2014, de: http:// www.transchordian.com/2012/09/the-lack-of-narrative-asnarrative/\#more-203

Van Dijk, J. (2009). Theorizing agency in user-generated content. Media, Culture \& Society, 31(1), 41-58.

Vernallis, C. (2013). Unruly media: YouTube, Music Video, and the New Digital Cinema. Oxford: Oxford University Press.

Winter, C. (2013). Media Development and convergence in the music industry. En Diehl, S. \& Karmasin, M. (eds.), Media and convergence management (pp. 261-281). Berlin, Heidelberg, Nueva York: Springer Verlag GmbH.

Woomedia (2014). 20 tendencias de música digital y social media marketing en 2014. Recuperado el 3 de marzo de 2014, de http://www. woomedia.es/8/post/2014/01/20-tendencias-de-musica-digitaly-social-media-marketing-para-2014.html 